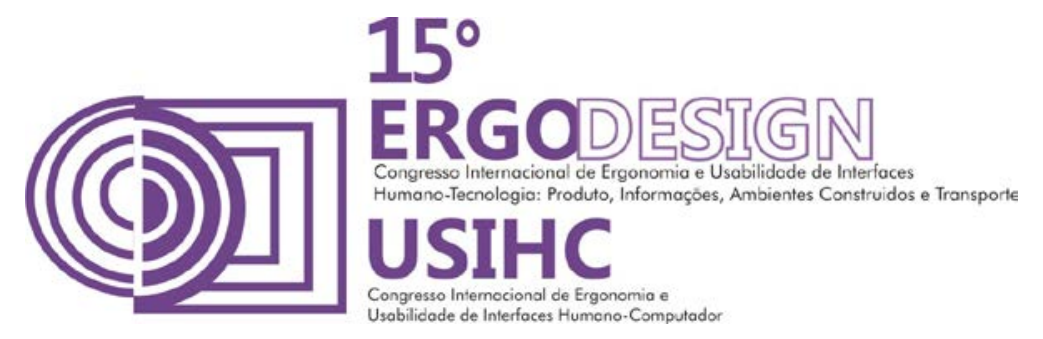

\title{
A IMPORTÂNCIA DOS ASPECTOS ERGONÔMICOS NO DESIGN DE EMBALAGENS: UM ESTUDO BIBLIOMÉTRICO
}

\section{THE IMPORTANCE OF ERGONOMIC ASPECTS IN PACKAGING DESIGN: A STUDY BIBLIOMETRIC}

\author{
SILVA, João Carlos Riccó Plácido da (1) \\ TRABACHINI, Taty Any Mizoguchi (2) \\ PASCHOARELLI, Luis Carlos (3) \\ (1) PPGDesign-UNESP, Doutorando \\ e-mail:joaocarlos placido@hotmail.com \\ (2) DepDesign-UNESP, Iniciação Científica \\ e-mail: ta trabachini@yahoo.com.br \\ (3) PPGDesign-UNESP, Doutor \\ e-mail: paschoarelli@faac.unesp.br
}

\begin{abstract}
RESUMO
O design de embalagens evoluiu expressivamente nas últimas décadas e compõem um mercado cada vez mais exigente. Seus diferentes aspectos podem ser um fator decisivo na comercialização e uso dos produtos. A ergonomia da embalagem é um aspecto de grande interesse, pois pode contribuir diretamente em diferentes atributos, tais como segurança e usabilidade. Este estudo objetivou analisar o quanto tem sido estudado os aspectos ergonômicos no design de embalagens. A partir de um levantamento bibliométrico, foi possível identificar a demanda da ergonomia no design de embalagens (estrutural ou visual), e o quanto essa questão pode influenciar a opinião e preferência dos usuários.
\end{abstract}

Palavras Chave: Design; Ergonomia; Embalagem.

\section{ABSTRACT}

The packaging design has evolved significantly in recent decades and make up an increasingly demanding market. Its different aspects can be a deciding factor in the marketing and use of products. The ergonomics of the package is an aspect of great interest because it can contribute directly to different attributes such as security and usability. This study aimed to analyze how much has been studied ergonomic aspects in packaging design. From a bibliometric survey, it was possible to identify the ergonomics of demand in packaging design (structural or visual), and how this question can influence opinion and preference of users . 


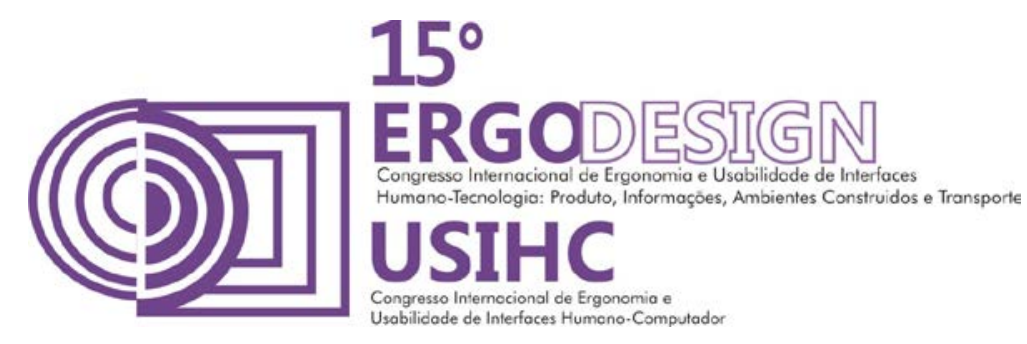

Keywords: Design; Ergonomics; Packaging.

\section{INTRODUÇÃO}

A embalagem sempre teve um papel importante nas últimas décadas, porém na atualidade a mesma passou a desempenhar diferentes funções, se tornando um fator cada vez mais influente diante dos aspectos mercadológicos, econômicos e culturais.

Segundo Moura e Banzato (2000), o sentido mais vasto do termo embalagem é de um sistema que resulta da integração da arte, ciência e técnicas de produção a fim de gerar condições excelentes de transporte, armazenamento, distribuição, comercialização e consumo. Além disso, para Santos e Castro (1998), as mesmas podem ser compreendidas como um veículo capaz de organizar um sistema de comunicações, porque podem produzir informações que são posteriormente transformadas em decisões.

No modo de vida contemporâneo, as embalagens são elementos imprescindíveis, uma vez que são responsáveis pela circulação de produtos e mercadorias pelo mundo. As mesmas também são instrumentos de comunicação e marketing, além de possuírem um importante papel no setor produtivo. Segundo a Fundação Getúlio Vargas, o setor de embalagem constitui um importante segmento da indústria brasileira representando um faturamento anual na ordem de $\mathrm{R} \$ 28$ bilhões.

A embalagem é também uma ferramenta de marketing, sendo que nos produtos de consumo é também um instrumento de comunicação e vendas. Na maioria dos casos, ela é a única forma de comunicação que o produto dispõe, uma vez que grande maioria dos produtos expostos em supermercados não tem qualquer apoio de comunicação ou propaganda (MESTRINER, 2001). Além disto, a embalagem auxilia no processo comunicacional com os seus clientes e guarnecem proteção, segurança e armazenamento corretos (SILVA, 2005).

\section{EMBALAGEM E ERGONOMIA}

De acordo com Strunck (1989), numa sociedade como a nossa, aceleradamente competitiva, só conquistam posições de destaques as ideias que se tornam conhecidas. E para que este conhecimento seja alcançado da forma mais rápida e eficaz, é da maior relevância a qualidade de suas manifestações visuais. Com o progressivo aumento da competitividade no mercado, requisitos como parâmetros ergonômicos e de usabilidade tanto na parte estrutural, e principalmente visual e informacional são decisivos na escolha dos consumidores e, portanto, no reconhecimento dos produtos.

O Design de embalagens é diferente de praticamente todas as outras disciplinas de design, porque seu objetivo primário é, simplesmente, reconhecimento. Uma embalagem de sucesso requer, em primeiro lugar e, sobretudo, consistência. A embalagem se torna um símbolo de identidade que é constante, familiar e instantaneamente reconhecível (MILTON, 1991).

A ergonomia apresenta ferramentas importantes, as quais procuram conhecer as capacidades e limitações dos usuários, disponibilizando dados essenciais para o desenvolvimento de um bom produto, embalagem, identidade visual, etc. Numa definição adotada pela Associação 


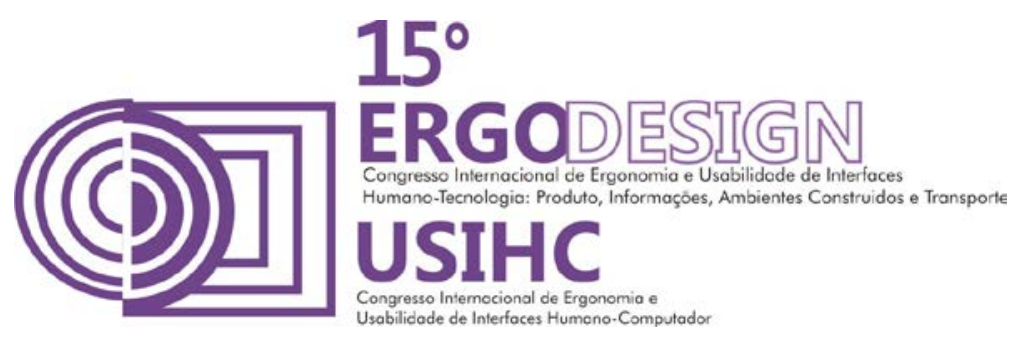

Internacional de Ergonomia - IEA (2005), a mesma pode ser considerada como uma disciplina científica relacionada ao entendimento das interações entre os seres humanos e outros elementos ou sistemas, e à aplicação de teorias, princípios, dados e métodos a projetos a fim de otimizar o bem estar humano e a performance global do sistema.

No conjunto da embalagem estão presentes os sistemas informacionais em que o produto se comunica com o usuário de diversas maneiras, seja através de detalhes básicos como nome, peso ou quantidade, ingredientes e instruções, ou ainda relacionadas à percepção, como o uso das cores, a legibilidade, a leiturabilidade, sendo de grande importância a compreensão dos usuários. Além disso, os sistemas de informação possuem a função de despertar a atenção e o desejo de compra do consumidor, tornando-se, muitas vezes, o sinônimo da marca. A ergonomia informacional faz o uso dos princípios da teoria da informação, ou seja, enviar essa informação correta para a pessoa certa no momento pretendido, de forma mais eficaz e eficiente, trazendo assim uma satisfação ao usuário respeitando sempre a sua diversidade. Para alcançar este objetivo ela contempla a cognição e a percepção e abrange os aspectos da linguagem verbal e não verbal (MARTINS E MORAES, 2002).

O projeto de uma embalagem possui duas importantes etapas: a forma - design estrutural - e o visual - elementos gráficos. Na parte estrutural, há diversos tipos de embalagens, envolvendo uma grande variedade de formas, tamanhos, materiais, etc. Já o visual inclui informações verbais e a não verbais. As verbais são compostas por elementos textuais, geralmente o nome do produto, informações nutricionais, ingredientes, entre outros e as não verbais refere-se ao logotipo, figuras, cores, etc. O design estrutural e os elementos gráficos não devem ser considerados elementos separados, já que ambos fazem parte da identificação do produto e compõem a embalagem como um todo.

Segundo Mestriner (2001), a embalagem foi incorporando elementos de comunicação que foram traduzidos em objetos, constituindo ao longo do tempo um repertório iconográfico, uma espécie de vocabulário visual da embalagem. Sendo assim, tanto os aspectos bidimensionais quanto os tridimensionais fazem parte da comunicação da embalagem.

\section{A COMUNICAÇÃO VISUAL DAS EMBALAGENS E A PERCEPÇÃO HUMANA}

A grande força da embalagem está no fato de o marketing ser uma batalha de percepções e não de produtos. Nesse sentido, a embalagem tem poder de fazer com que o produto seja percebido de uma certa maneira agregando a ele novos valores e significados (MESTRINER, 2001). Dessa forma, as empresas buscam cada vez mais recursos para conquistar os consumidores através de embalagens atraentes.

A comunicação visual e as ideias transmitidas através dela podem definir o reconhecimento de um produto, visto que os elementos e a organização visual mexem com a percepção humana, possibilitando uma interação entre as informações apresentadas. Esses estudos surgiram como reação às teorias contemporâneas estabelecidas e que se fundamentaram apenas na experiência individual e sensorial. Partem do princípio de que o objeto sensível não é apenas um pacote de sensações para o ser humano, pois a percepção está além dos elementos fornecidos pelos órgãos sensoriais. Eles se fundamentaram nas afirmações de Kant, de que os elementos por nós percebidos são organizados de forma a fazerem sentido e não somente através de associações com o que se conhece anteriormente. (GOMES FILHO, 2000). 


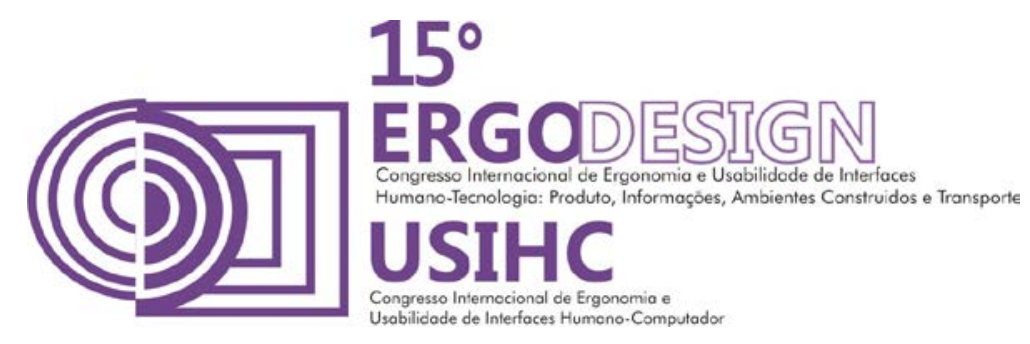

Para Engel, Blackwell e Miniard (2000), estas percepções são compreendidas porque os estímulos da interpretação são altamente subjetivos e baseiam-se no que o consumidor tem da experiência anterior, sobre o número de explicações plausíveis que podem imaginar, sobre os motivos e os interesses no momento da percepção e da clareza do estímulo em si. Com isso, os princípios da Gestalt, um campo da psicologia que estuda a organização da percepção humana, são bastante utilizados na transmissão de informações, visto a grande importância que a parte visual apresenta.

Os princípios e categorias da Gestalt são um sistema de leitura visual que verifica como diferentes elementos da forma podem ser lidos e compreendidos de maneiras distintas pela percepção humana. William James, filósofo norte-americano, influenciou muito os fundamentos dessa escola, ao considerar que as pessoas não observam os objetos como pacotes formados por sensações, mas como uma unidade, concluindo que a percepção do todo é maior que a soma das partes captadas. A fenomenologia de Emund Husser também teve influência na formação da Gestalt. Ela baseia-se no princípio de que toda consciência relaciona-se com alguma coisa e, nesse sentido, não é uma substância, mas sim uma atividade constituída por atos, percepção, imaginação, especulação, volição, paixão, entre outros, com os quais é possível visar algo. (DONDIS, 1997).

O cérebro possibilita uma interação entre os elementos apresentados a ele, utilizando-se de princípios da organização perceptual. Com isso, o mesmo possui a capacidade de autoorganização dos estímulos recebidos pelos sentidos. De acordo com os princípios da Gestalt, existem oito aspectos principais na percepção de objetos e formas: Unidade, Segregação, Unificação, Fechamento, Continuidade, Proximidade, Semelhança e Pregnância da Forma. (GOMES FILHO, 2000). A Unidade pode ser constituída por um único elemento, que se define por si só, ou como parte de um todo, sendo um conjunto de vários elementos que se tornam um todo. A segregação é a capacidade da percepção em separar, identificar ou destacar unidades formais em um todo ou em partes deste. A Unificação se configura na igualdade ou semelhança dos estímulos produzidos pelo campo visual contido no objeto. O fechamento constitui-se uma sensação de fechamento visual da forma, em que a mesma se dirige espontaneamente para uma ordem espacial que tende à formação de unidades em um todo.

A Continuidade é a impressão visual, uma tendência dos objetos acompanharem uns aos outros, a fim de permitirem uma boa continuidade dos elementos. A Proximidade pode ser observada quando mais objetos tendem a ser vistos juntos, no intuito de se tornar um todo, ou diferentes unidades dentro deste todo. A Semelhança se constitui em uma igualdade de formas e desperta a tendência de construir unidades e estabelecer agrupamentos de partes semelhantes. Pregnância da forma pode ser definida como qualquer padrão de estímulo que tende a ser visto como uma estrutura simples.

\section{OBJETIVOS}

O processo projetual e o design ergonômico no desenvolvimento de embalagens são fundamentais, tanto em sua parte estrutural quanto na criação da identidade visual. O presente estudo objetivou analisar o quanto tem sido estudado os aspectos ergonômicos no design de embalagens e para tanto propôs-se realizar um levantamento de pesquisas ergonômicas relacionadas ao setor de embalagens. Sendo assim, foi realizada uma análise bibliométrica 


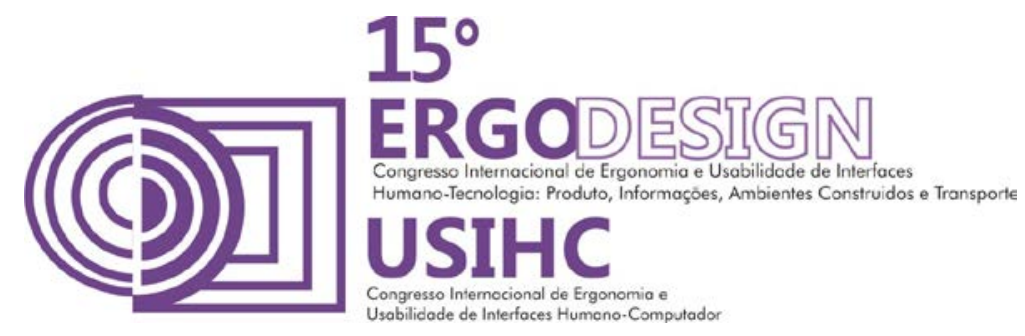

sobre a quantidade de artigos publicados em eventos científicos de grande importância dentro do cenário nacional: P\&D; Ergodesign; Abergo; USIHC e IDEMi.

\section{MATERIAIS E MÉTODOS}

Primeiramente, foi feita uma análise bibliométrica de artigos aprovados e publicados (oral e pôsteres) em cinco eventos a partir do ano de 1999. Foram consideradas 6 edições do P\&D (2002-2012); 10 edições do Ergodesign (2001-2010); 7 edições da Abergo (1999-2002; 2004; 2006 e 2008); 6 edições do USIHC (2003-2008) e 1 edição do IDEMi (2012).

As palavras chave utilizadas para a busca de artigos foram "embalagem" e "ergonomia", sendo a última considerada apenas as que se relacionavam a embalagens. Após a seleção de acordo com o assunto de interesse, foi realizada uma análise da quantidade de estudos desenvolvidos e publicados por evento e por ano. Os artigos foram acessados individualmente, sendo separados também por temas, através do foco de pesquisa.

Foram considerados artigos sobre embalagens e sua ergonomia, porém os mesmos referiam-se a diversos tipos de embalagens e campos da ergonomia. Os resultados foram analisados com estatística descritiva, mas permitiram uma ampla análise sobre as publicações.

\section{RESULTADOS E DISCUSSÕES}

Foram encontrados 83 artigos, sendo 59 artigos do P\&D; 13 artigos do Ergodesign; 5 artigos da Abergo; 5 do artigos do IDEMi e 1 artigo do USIHC. Inicialmente os artigos foram separados por evento e por ano, e para a análise desses dados foi construído um gráfico de número de artigos por ano (Figura 01). Podemos notar uma variação irregular de pesquisas publicadas, sendo que nos anos pares há uma quantidade maior devido ao evento P\&D, que possui mais publicações dentre os eventos da amostra.

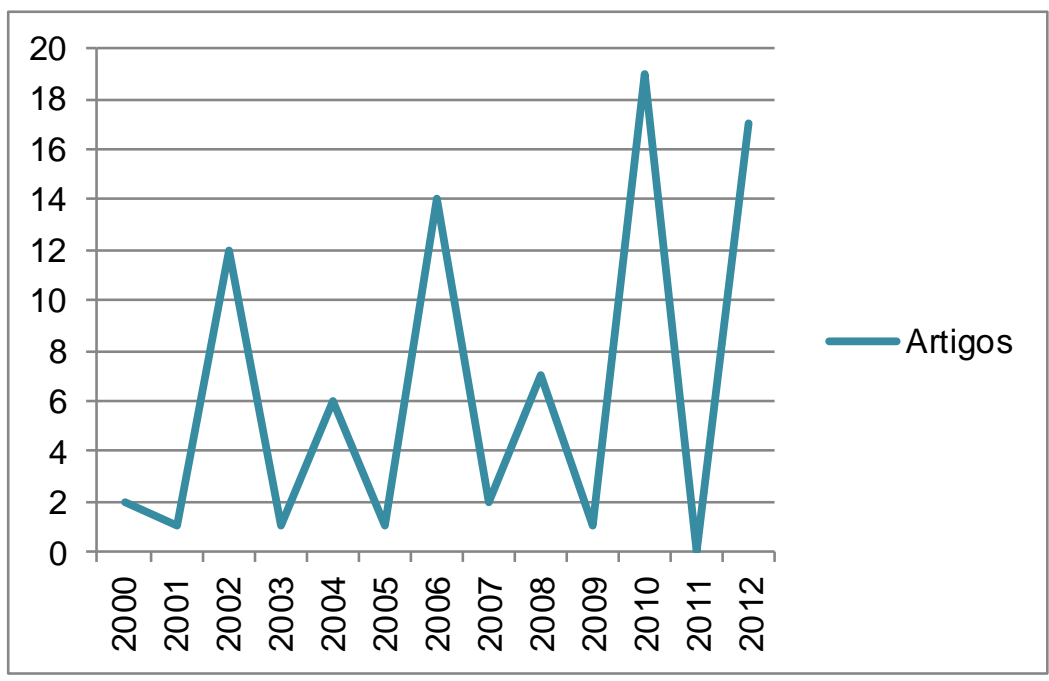

Figura 01: Gráfico de número de artigos por ano 


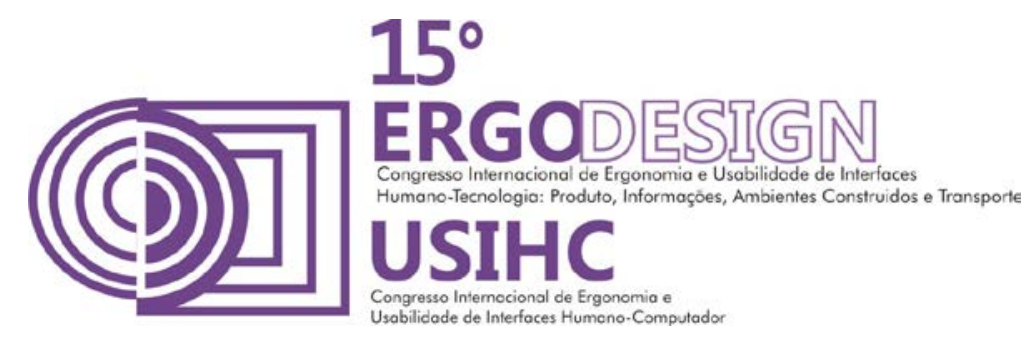

A partir desse levantamento foram realizadas as seguintes subdivisões temáticas: Ergonomia Informacional; Ergonomia da embalagem (Estrutura); Comunicação visual (Percepção); Desenvolvimento de embalagem ou identidade visual e outros. Através desses dados foi analisada a frequência de artigos por tema (Figura 02), que permite estudar a quantidade de pesquisas realizadas por assunto de acordo com a amostra utilizada.

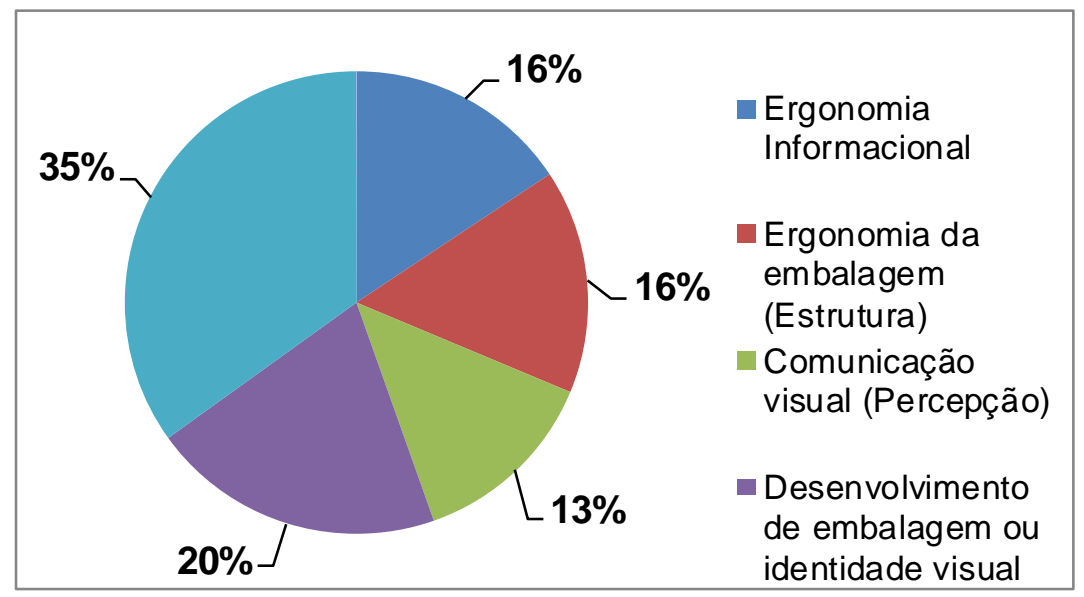

Figura 02: Gráfico de frequência de artigos por tema

Os artigos referentes à diversos campos da ergonomia (representados no gráfico como "Outros"), apresentou frequência de $35 \%$ da amostra total. Nessa categoria, foram inclusos temas mais amplos envolvendo embalagem como a história; funções; materiais; sustentabilidade; novas tecnologias e embalagens interativas; redução de desperdício e reutilização; influências da diversidade cultural no design de embalagens; análise ergonômica do posto e condições de trabalho do setor de embalagem, entre outros. Isto demonstra o quão amplo o design de embalagem pode ser relacionado aos aspectos ergonômicos de projeto e de produção.

O segundo tema com maior número de publicações (20\%) foi o desenvolvimento de embalagem ou identidade visual. As pesquisas analisam a funcionalidade e a comunicação visual das embalagens, detectando diversos problemas. Posteriormente, foram desenvolvidas soluções que pudessem melhorar os produtos nesses aspectos, tornando-os mais acessíveis para 0 consumo.

Nas áreas de ergonomia da embalagem estrutural e ergonomia informacional, ambas obtiveram $16 \%$ da amostra. A primeira trata-se da parte estrutural das embalagens, verificando o design e a funcionalidade das mesmas. Já a segunda refere-se à parte de comunicação e transmissão de informações dos produtos para os consumidores, envolvendo aspectos como legibilidade, leiturabilidade, compreensão, em que, através das publicações, é possível verificar uma deficiência nesse setor. Na maioria das pesquisas, foram apontados os problemas quanto à 


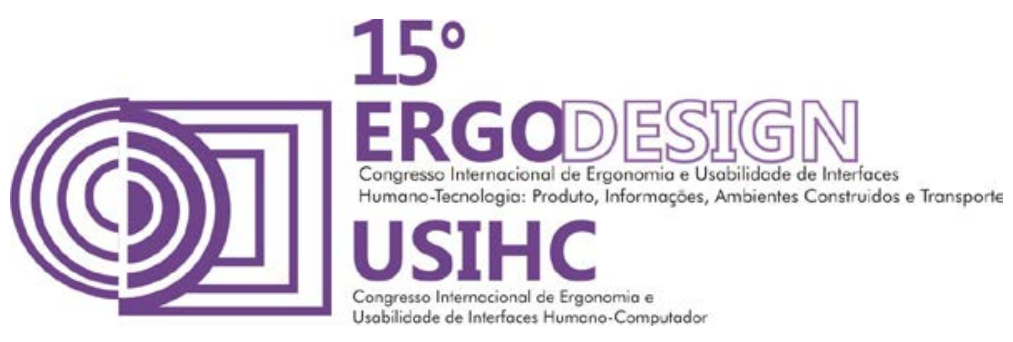

parte estrutural ou informacional e as consequências sofridas pelos usuários. Algumas ainda citam soluções para a melhoria dos produtos, porém não apresentam o desenvolvimento das mesmas, já que esse não é o objetivo dessas pesquisas.

O tema sobre comunicação visual, com foco na percepção humana, é o menos frequente com $13 \%$. As pesquisas ressaltam a importância de um bom desenvolvimento gráfico, que é capaz de mexer com a organização perceptual humana. Além disso, mostram através de referências, enquetes, testes, que a parte visual dos produtos pode influenciar nas escolhas dos consumidores. Paschoarelli e Bonfim (2013) apresentam alguns exemplos do ponto de vista do design informacional de embalagens, cujos aspectos ergonômicos e de usabilidade são bastante precários, ainda que os projetos apresentados tenham sido relativamente bem apresentados.

\section{CONCLUSÕES}

A partir do levantamento bibliométrico e a análise dos resultados, podemos concluir que os estudos relacionados às embalagens ainda não apresentam grande abrangência nos principais eventos científicos nas áreas da Ergonomia e do Design. Porém dentre os artigos sobre embalagens, os assuntos relacionados à ergonomia são muito frequentes. Sendo assim, podese dizer que a importância da ergonomia vem sendo cada vez mais reconhecida, assim como o design das embalagens, tanto no âmbito estrutural (Produto) quanto no visual (Informacional).

Com a grande competitividade do mercado, a preocupação com a opinião e escolha dos consumidores vem se ampliando. Muitas empresas buscam recursos por meio da inovação, ergonomia, identidade visual, entre outros aspectos capazes de conquistar e criar um vínculo com os consumidores e usuários. Porém, mesmo com o aumento da exigência no mercado e dos consumidores, os problemas de falta de ergonomia, simplicidade e clareza nas informações, legibilidade, presentes em embalagens ainda são muito frequentes.

Pesquisas e estudos nessa área ainda são muito relevantes, já que o setor de embalagens constitui um segmento de grande importância na indústria mundial. Além de analisar os problemas de interface entre consumidores/usuários e as embalagens, tais estudos podem auxiliar em melhorias e progresso desse setor, visando cada vez mais o seu crescimento.

\section{REFERÊNCIAS BIBLIOGRÁFICAS}

DONDIS, D. A. A sintaxe da imagem visual. Barcelona: Editora Gustavo Gili, 1997.

ENGEL, J.; BLACKWELL, R.; MINIARD, P. Comportamento do Consumidor. Rio de Janeiro: LTC, 2000.

GOMES FILHO, J. Gestalt do Objeto: Sistema de Leitura Visual da Forma. São Paulo: Escrituras Editora, 2000.

MARTINS, L.B. \& MORAES, A. Ergonomia Informacional: Algumas Considerações sobre o Sistema Humano-mensagem Visual. In Gestão da Informação na Competitividade das Organizações. Recife: Editora Universitária da UFPE, 2002.

MESTRINER, F. Design de embalagem: curso básico. São Paulo: Makron Books, 2001.

MILTON, H. Packaging Design. Londres: The Design Council, 1991. 


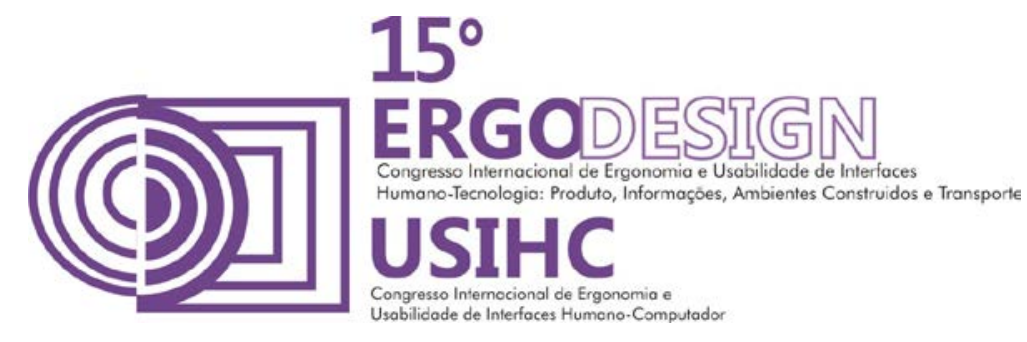

MOURA, R. e BANZATO, J. Embalagem, unitização e conteinerização. $3^{a}$ ed. São Paulo: IMAM, 2000.

PASCHOARELLI, L.C. e BONFIM, G.H.C. Ergonomics and interfaces of traditional

information systems - Packaging. Infodesign. 10 (03): 313-322. 2013.

SANTOS, R. e CASTRO, V. Uma proposição sistêmica para o desenvolvimento de embalagens. In: RAE. São Paulo, 1998.

SILVA, C. R. L. Instruções das embalagens de consumo: um estudo. In $2^{\circ}$ Congresso Internacional de Design da Informação. São Paulo: Senac. 2005.

STRUNCK, Gilberto L. Identidade Visual - A direção do Olhar. Rio de Janeiro: Europa, 1989. 